\title{
Genetic variability predicts common frog (Rana temporaria) size at metamorphosis in the wild
}

\author{
D Lesbarrères ${ }^{1,4}$, DS Schmeller ${ }^{2,4}$, CR Primmer ${ }^{3}$ and J Merilä ${ }^{4}$ \\ ${ }^{1}$ Department of Biology, Laurentian University, Sudbury, Ontario, Canada; ${ }^{2}$ Department of Conservation Biology, Helmholtz Centre for \\ Environmental Research - UFZ, Leipzig, Germany; ${ }^{3}$ Department of Biology, University of Turku, Turku, Finland and ${ }^{4}$ Ecological \\ Genetics Research Unit, Department of Biological and Environmental Sciences, University of Helsinki, Helsinki, Finland
}

\begin{abstract}
We investigated associations between genetic variability and two fitness-related traits - size and age at metamorphosis in two subartic populations of the common frog, Rana temporaria. We found that metamorphic size was positively correlated with individual heterozygosity (as estimated using eight microsatellite loci) and that maternal heterozygosity also explained a significant amount of variation in this trait. In contrast, age at metamorphosis was only explained by environmental factors. Since size at metamorphosis is
\end{abstract}

positively correlated with fitness in amphibians, these results suggest that genetic variability may be an important component of individual fitness in common frogs. The environmental variation underlying timing of metamorphosis may indicate that strong selection pressure on this trait in the Nordic environment is likely to override genetic effects.

Heredity (2007) 99, 41-46; doi:10.1038/sj.hdy.6800961; published online 2 May 2007

Keywords: Rana temporaria; offspring fitness; microsatellites; heterozygosity; maternal effects

\section{Introduction}

Fitness and/or lifetime reproductive success, defined as the total number of offspring produced which reach maturity is extremely difficult to measure especially in taxa with external fertilization. In fact, two components of total reproductive success - reproductive lifespan and offspring survival - are practically impossible to measure in some cases because of difficulties in tracking individuals throughout their lifetime. As a result, indicators of fitness, which are easier to measure, but less accurate, are often used. For instance, reproductive output, that is, the number or size of offspring produced per mating event, is commonly used as a proxy for total reproductive success (Gibbons and McCarthy, 1986; Ryser, 1989), and several studies have investigated the variation in these traits to assess variation in individual fitness (Roff, 1992).

The relationship between fitness and genetic variability has often been investigated through associations between marker-based measures of genetic variability and fitness-related traits (e.g., Allendorf and Leary, 1986; Mitton, 1997; David, 1998; Lesbarrères et al., 2005). Rate of development or growth and survival have frequently been targeted in research, while investigation of reproductive success is more rare (but see McAlpine, 1993; Slate et al., 2000). In general, life history traits should exhibit high levels of dominance variance and should therefore be more strongly affected by inbreeding depression than more weakly selected morphometric traits (Roff, 1997; Merilä and Sheldon, 1999). Thus,

Correspondence: Dr D Lesbarrères, Department of Biology, Laurentian University, Ramsey Lake Road, Sudbury, Ontario, Canada P3E 2C6.

E-mail: dlesbarreres@laurentian.ca

Received 7 August 2006; revised 10 January 2007; accepted 16 February 2007; published online 2 May 2007 assuming that the relationship between fitness and genetic variability results from effects of homozygosity at genome-wide distributed loci (i.e., general effect hypothesis; Hansson and Westerberg, 2002; Lesbarrères et al., 2005), there is potential for a link between genetic variability and reproductive success. Recent work (Balloux et al., 2004; Slate et al., 2004) has suggested problems in detection of genetic variability-fitness correlations (GFCs) at the individual level as well as difficulties in distinguishing between the underlying genetic causes (Tsitrone et al., 2001; Hansson and Westerberg, 2002). One problem is that when estimated from only a handful of markers, the correlation between genome-wide heterozygosity and its estimate obtained from these markers is very close to zero (Balloux et al., 2004). However, there are indeed some convincing case studies, which have been able to demonstrate GFCs using life history traits (Rowe et al., 1999; Markert et al., 2004; Lesbarrères et al., 2005; Da Silva et al., 2006).

In amphibians, while stochasticity is usually observed between the number of females present, the number of eggs deposited and the number of metamorphs emerging (Richter et al., 2003), there is a general relationship between fitness and both size and age at metamorphosis (reviewed by Altwegg and Reyer, 2003). Individuals metamorphosing at a large size have an increased chance of survival during the following terrestrial stage. They also grow faster and are larger at maturity than individuals metamorphosing at smaller sizes supporting the assumption that size at metamorphosis positively relates to future fitness. Similarly, age at metamorphosis is an important life history trait associated with survival probability. It is dependant on growth rate and shows high variability in amphibian populations from different environments (Merilä et al., 2000, 2004). Hence, the 
fitness of anuran larvae is of much interest for understanding patterns of reproductive success in wild populations, as differences in size and/or age at metamorphosis persist throughout the entire lifespan of an individual (Berven and Gill, 1983; Smith, 1987).

Variation in maternal effects is conventionally considered to be the main factor driving egg size variation (Kaplan, 1998; Laugen et al., 2002; Räsänen et al., 2005). Maternal effects could thus provide a process of transgenerational phenotypic plasticity, where the environment experienced by the mother indirectly determines the phenotype of her offspring (Mousseau and Fox, 1998). Consequently, phenotypic variation in female traits has been put forward as the major component of offspring quality (Roff, 1992). However, beyond the effects of alleles inherited, genetic variability of the parents, in general, and the mother, in particular, may play a role in determining offspring fitness (McAlpine, 1993).

The aim of our study was to explore the relationship between genetic variability and fitness in the wild as well as to investigate the possible relationship between parental genetic variation and offspring life history trait variation in two Rana temporaria populations in northern Finland. Under the assumption that (1) genetic variability in microsatellite loci reflects variability in genomewide heterozygosity as postulated by the general effect hypothesis (cf. Lesbarrères et al., 2005), and that (2) size and age at metamorphosis are positively related to fitness, we predicted a positive relationship between these two metamorph life history traits and genetic variability.

\section{Methods}

\section{The study species and populations}

The common frog ( $R$. temporaria) is the most widely distributed amphibian species in Europe (Gasc et al., 1997) and is a typical explosive breeder (sensu Wells, 1977). The spawning period lasts about 20 days, although the majority of the eggs are laid during the first few days of the breeding season (Haapanen, 1982). Both larval and adult life history traits display extensive geographic variation (Fog et al., 1997; Miaud et al., 1999; Miaud and Merilä, 2001). In northern Finland, the larval development from hatching to metamorphosis ranges from 63 to 113 days (Koskela, 1973) and local adaptation to shorter growth season in the north, as compared to more southern populations, has been suggested (Merilä et al., 2000).

The Kilpisjärvi study area lies within a mountainous landscape in a border zone between maritime and continental climates in northern Finland $\left(69^{\circ} 03^{\prime} \mathrm{N}, 20^{\circ}\right.$ $47^{\prime}$ E). Kilpisjärvi is one of the coldest continental European locations in regards to the annual mean temperature $\left(-2.3^{\circ} \mathrm{C}\right)$. The area is covered in snow from mid-October to mid-June. The duration of the growth season in the last 50 years has varied from 79 to 127 days (mean 101.12 \pm 12.12 days; Järvinen, 1987; Kilpisjärvi biological station, unpublished data). In 1999, when the study was conducted, the growing season was 89 days long. Two ponds which differ in several environmental characteristics were sampled. The first pond (hereafter pond $\mathrm{T})$ is rather small $\left(530 \mathrm{~m}^{2}\right)$ with a maximum depth of ca. $60 \mathrm{~cm}$. It is situated on the edge of a subarctic open marsh which usually dries out during hot and arid summers. The second pond (hereafter pond $\mathrm{P}, 220 \mathrm{~m}^{2}$ surface area, $1.6 \mathrm{~m}$ depth) is situated on the edge of the same marsh (the distance between the two ponds is $520 \mathrm{~m}$ ) and is much cooler than the pond $\mathrm{T}$ because of the presence of ground water.

\section{Ecological data}

Continuous trapping, initiated before the emergence of frogs from hibernation, allowed the collection of all adult frogs returning to their breeding ponds. Daily monitoring of the breeding sites (4-8 visits pond ${ }^{-1}$ day $^{-1}$ ) allowed detection of the arrival and departure of frogs at the ponds. All captured individuals were sexed according to secondary sexual characters and morphology; weight (to nearest g) and snout-to-vent length (SVL; to nearest $0.5 \mathrm{~mm}$ ) were also measured. Thereafter, the traps were checked twice a day until the ponds were covered with ice. Daily monitoring allowed us to determine the exact day when a given metamorph emerged from a pond. In addition, the metamorphs were weighed to the nearest $0.001 \mathrm{~g}$ and a complete toe was excised under anaesthesia and immediately frozen at $-20^{\circ} \mathrm{C}$ for the purpose of the genetic analyses. A toe tip was also taken for genetic analyses from all adults captured. From mid-May to the end of September 1999, 423 offspring and 140 adults were collected by drift fencing at the two ponds. The sampling was completed by 19 September 1999 after which no metamorphs emerged. By this date, however, all the adults had not yet left the pond and the sample size for the departure date variable was thus small.

\section{Genetic data}

Both adults and metamorphs were analyzed at eight polymorphic microsatellite loci: Rt2Ca2-22 and Rt2Ca25 (T Garner, unpublished data; Lesbarrères et al., 2005), RRD590 (Vos et al., 2001), Rt $\mu \mathrm{H}$ (Pidancier et al., 2002), RtSB03 (Berlin et al., 2000), Rtemp $\mu 4$, Rtemp $\mu 5$ and Rtemp $\mu 7$ (Rowe and Beebee, 2001b). DNA extraction, polymerase chain reaction amplifications and gel electrophoresis were performed as described by Palo et al. (2003).

We used the program MICROCHECKER (van Oosterhout et al., 2004) to test for null alleles and erroneous genotyping due to stuttering. A total of 301 metamorphs were assigned to potential parents (26 males and 52 females) using the program PAPA, which assigns offspring to the most likely parental pair (likelihood approach) and allows for genotyping errors and mutations as reason for alterations of the genotype of the offspring relative to potential parents (Duchesne et al., 2002). To correct for errors resulting from miss-genotyping and mutations, we set the global level of transmission error to 0.01 , meaning that $1 \%$ of all single-locus genotypes of the analyzed offspring might show genotyping errors or mutations; and the error distribution to 10, delimiting the assignment of mismatching offspring genotypes to one category up and down (strict stepwise model) relative to the parental genotype.

Observed heterozygosity was used as an estimate of intraindividual genetic variability in the study. This was calculated as the number of heterozygous microsatellite 
loci observed for an individual divided by the total number of loci genotyped for that individual. Only individuals for which at least six loci were successfully genotyped were included in the study.

\section{Analyses}

Two offspring variables were investigated in this study: the day of departure from the pond, and their weight on this date. For each dependent variable, a linear model was used to assess the importance of phenotypic versus genetic variables. For the weight at metamorphosis, the explanatory continuous variables were the genetic variability (observed heterozygosity) of the offspring $\left(H_{\mathrm{O}}\right)$, the sire $\left(H_{\mathrm{S}}\right)$ and the dam $\left(H_{\mathrm{D}}\right)$, the size of both the sire $\left(\mathrm{SVL}_{\mathrm{S}}\right)$ and the dam $\left(\mathrm{SVL}_{\mathrm{D}}\right)$, the weight of both the sire $\left(W_{\mathrm{S}}\right)$ and the dam $\left(W_{\mathrm{D}}\right)$ and the pond they originated from (Pond) as a classification variable. For the day the metamorphs were captured, the explanatory continuous variables were $H_{\mathrm{O}}, H_{\mathrm{S}}, H_{\mathrm{D}}$, the arrival day of both the sire $\left(A_{\mathrm{S}}\right)$ and the dam $\left(A_{\mathrm{D}}\right)$, the departure day of both the sire $\left(D_{\mathrm{S}}\right)$ and the dam $\left(D_{\mathrm{D}}\right)$, the offspring weight $\left(W_{\mathrm{O}}\right)$ and the pond they originated from (Pond) as a classification variable.

We assessed the effects of each explanatory variable based on Type III sums of squares, which reflect the influence of a variable after all other explanatory variables in the model have been accounted for (Sokal and Rohlf, 1995). For the analysis of the offspring weight, an analysis of variance (ANOVA) was used to further explore the importance of genetic variables by comparing the full model to a model including only $\mathrm{SVL}_{\mathrm{S}}, \mathrm{SVL}_{\mathrm{D}}$, $W_{\mathrm{S}}, W_{\mathrm{D}}$ and Pond. All statistical analyses were performed with $\mathrm{R}$ statistical package ( $\mathrm{R}$ Development Core Team, 2003).

\section{Results}

Both within and among ponds we captured significantly longer and heavier females (among ponds: ANOVA: $\mathrm{F}_{1,136}=32.61, P<0.001$ and $\mathrm{F}_{1,136}=53.62, P<0.001$ for SVL and weight, respectively; Table 1). Among both ponds, males and females arrived at the same time $\left(\mathrm{F}_{1,136}=0.43, P=0.51\right.$; Table 1$)$ but females left significantly earlier than males $\left(\mathrm{F}_{1,84}=6.12, P=0.02\right.$; Table 1$)$. We did not observe any difference in genetic variability among sexes $\left(F_{1,136}=0.002, P=0.97\right.$; Table 1$)$ nor among ponds (pond $\mathrm{T}, H=0.56 \pm 0.16$; pond $\mathrm{P}, H=0.60 \pm 0.17$; ANOVA: $\left.\mathrm{F}_{1,83}=2.83, P=0.1\right)$.

Both the mean offspring weight and the mean day of capture differed among ponds. The day of capture on pond $\mathrm{T}$ was significantly earlier than on pond $\mathrm{P}$ (ANOVA: $F_{1,299}=53.74, P<0.001$; Table 2 ) and the mean offspring weight was significantly higher on pond $\mathrm{T}$ than on pond $\mathrm{P}$ (ANOVA: $\mathrm{F}_{1,298}=10.51, P=0.001$; Table 2 ). However, there was no significant correlation between the offspring weight and the day of capture in either of the ponds (pond $\mathrm{P}: r=-0.07, \mathrm{df}=17, P=0.782$; pond T: $r=-0.07, \mathrm{df}=279, P=0.24$ ).

Offspring weight was significantly influenced by the pond of origin (ANOVA: $\mathrm{F}_{1,291}=10.9, P=0.001$; Table 3), offspring heterozygosity (ANOVA: $\mathrm{F}_{1,291}=13.33$, $P<0.001$; Table 2, Figure 1) and to a lesser extent by dam heterozygosity (ANOVA: $F_{1,291}=3.98, P=0.047$; Table 3). Additionally, there was a significant difference between the full model and the model without the
Table 1 Descriptive information and one-way ANOVA for Rana temporaria adult traits in two different ponds in northern Finland

\begin{tabular}{lcccrc}
\hline Trait & Pond & Males & Females & $d f$ & $F$ \\
\hline Weight & $\mathrm{P}$ & $37.12(6.99)$ & $46.61(7.5)$ & 1,78 & $28.68^{* * * *}$ \\
& $\mathrm{~T}$ & $39.77(8.42)$ & $46.13(8.2)$ & 1,56 & $6.32^{*}$ \\
SVL & P and T & $38.07(7.53)$ & $46.4(7.78)$ & 1,136 & $32.61^{* * *}$ \\
& $\mathrm{P}$ & $70.8(3.75)$ & $77.1(3.87)$ & 1,78 & $46.53^{* * * *}$ \\
& $\mathrm{~T}$ & $71.21(4.28)$ & $75.88(4.35)$ & 1,56 & $12.33^{* * *}$ \\
Arrival $^{\mathrm{a}}$ & $\mathrm{P}$ and T & $70.95(3.89)$ & $76.56(4.11)$ & 1,136 & $53.62^{* * *}$ \\
& $\mathrm{P}$ & $5.79(3.11)$ & $8.78(4.47)$ & 1,77 & 1.78 \\
& $\mathrm{~T}$ & $9.67(11.23)$ & $6.95(4.47)$ & 1,57 & $8.84^{* * b}$ \\
Departure $^{\mathrm{a}}$ & $\mathrm{P}$ and T & $7.28(7.48)$ & $7.97(4.54)$ & 1,136 & 0.43 \\
& $\mathrm{P}$ & $19.89(10.16)$ & $14.77(7.26)$ & 1,60 & $5.1^{*}$ \\
& $\mathrm{~T}$ & $17.38(11.65)$ & $13.25(7.08)$ & 1,22 & 1.17 \\
H & $\mathrm{P}$ and T & $19.15(10.46)$ & $14.36(7.18)$ & 1,84 & $6.12^{*}$ \\
& $\mathrm{P}$ & $0.59(0.22)$ & $0.61(0.14)$ & 1,77 & 0.14 \\
& $\mathrm{~T}$ & $0.57(0.14)$ & $0.55(0.16)$ & 1,57 & 0.07 \\
& $\mathrm{P}$ and T & $0.58(0.19)$ & $0.58(0.15)$ & 1,136 & 0.00
\end{tabular}

Abbreviation: df, degree of freedom.

Weight $(\mathrm{g})=$ mean $( \pm$ s.e. $)$ weight of males/females; SVL $(\mathrm{mm})=$ mean $( \pm$ s.e. $)$ size of males/females; arrival $=$ mean $( \pm$ s.e. $)$ arrival day of males/females; departure $=$ mean $( \pm$ s.e. $)$ departure day of males/females; $H=$ mean ( \pm s.e.) genetic variability of males/ females.

$* P<0.05, * * P<0.01, * * * P<0.001$.

a 27 May 1999 was considered as day 0, as it was the date of the first adult captured.

${ }^{\mathrm{b}}$ Not significant when one late male arrived on day 36 was removed.

Table 2 Descriptive information about Rana temporaria offspring in two different ponds in northern Finland

\begin{tabular}{lrccccc}
\hline Pond & $\mathrm{N}_{O}$ & $\mathrm{~W}_{O}(g)$ & Day & $\mathrm{H}_{O}$ & $\mathrm{~N}_{S}$ & $\mathrm{~N}_{D}$ \\
\hline $\mathrm{P}$ & 19 & $0.32(0.05)$ & $106.32(6.29)$ & $0.63(0.16)$ & $10(25)$ & $12(55)$ \\
$\mathrm{T}$ & 282 & $0.36(0.03)$ & $88.39(8.91)$ & $0.57(0.16)$ & $16(16)$ & $40(44)$
\end{tabular}

$N_{\mathrm{O}}=$ number of metamorphs; $W_{\mathrm{O}}=$ mean ( \pm s.e.) offspring weight; day $=$ mean $( \pm$ s.e. $)$ number of days elapsed between the beginning of the study and capture day of the metamorphs; $H_{\mathrm{O}}=$ mean $( \pm$ s.e. $)$ offspring genetic variability; $N_{\mathrm{S}}=$ number of sires assigned (total number of males); $N_{\mathrm{D}}=$ number of dams assigned (total number of females).

Table 3 Linear models of Rana temporaria offspring weight accounting for effects of genetic variability of the offspring $\left(H_{\mathrm{O}}\right)$, the sire $\left(H_{\mathrm{S}}\right)$ and the dam $\left(H_{\mathrm{D}}\right)$, the size of both the sire $\left(\mathrm{SVL}_{\mathrm{S}}\right)$ and the dam $\left(\mathrm{SVL}_{\mathrm{D}}\right)$, the weight of both the sire $\left(W_{\mathrm{S}}\right)$ and the dam $\left(W_{\mathrm{D}}\right)$ and the pond they originated from (Pond)

\begin{tabular}{lccc}
\hline Source & $d f$ & $M S$ & $F$ \\
\hline$H_{\mathrm{O}}$ & 1 & 0.025 & $13.33^{* * * *}$ \\
$H_{\mathrm{S}}$ & 1 & 0.001 & 0.45 \\
$H_{\mathrm{D}}$ & 1 & 0.007 & $3.98^{*}$ \\
SVL $_{\mathrm{S}}$ & 1 & 0.001 & 0.60 \\
SVL $_{\mathrm{D}}$ & 1 & 0.000 & 0.08 \\
$W_{\mathrm{S}}$ & 1 & 0.000 & 0.10 \\
$W_{\mathrm{D}}$ & 1 & 0.000 & 0.17 \\
Pond & 1 & 0.020 & $10.90^{* *}$ \\
Model & 8 & & $3.70^{* * *}$ \\
Error & 291 & 0.002 & \\
$r^{2}$ & & 0.09 &
\end{tabular}

Abbreviations: $\mathrm{df}$, degree of freedom; MS, mean square; $r^{2}$, coefficient of determination.

${ }^{*} P<0.05,{ }^{* *} P<0.01,{ }^{* * *} P<0.001$ 


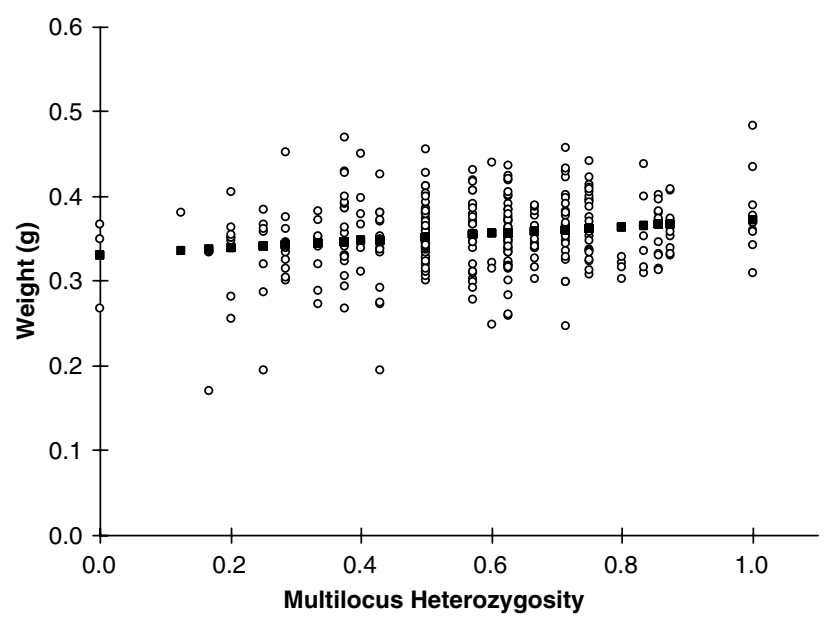

Figure 1 Predicted (filled squares) and observed (open circles) weight as a function of offspring multilocus heterozygosity in R. temporaria (multiple $r=0.19, P<0.001, n=301$ ).

genetic variables (i.e., $H_{\mathrm{O}}, H_{\mathrm{S}}$ and $H_{\mathrm{D}}$ ). The full model explained more of the variation than the reduced model (ANOVA: $\mathrm{F}_{3,291}=5.61, P<0.001$ ).

The day the metamorphs were captured was well explained by the pond of origin (ANOVA: $F_{1,23}=15.39$, $P<0.001$; Table 4), but there was also a significant positive association with the day of departure of the dam (ANOVA: $\mathrm{F}_{1,23}=4.29, P=0.05$; Table 3). The other possible variables did not explain variation in capture date (Table 4).

\section{Discussion}

The most salient result of this study was the positive correlation between genetic variability and offspring weight in the wild. Our results indicate that genetic variability is a reliable predictor of offspring size at the beginning of metamorph terrestrial life. This is consistent with previous results from an experimental study showing that the probability to survive until metamorphosis was higher for tadpoles with high genetic variability (Lesbarrères et al., 2005). While both simulation (Balloux et al., 2004) and empirical studies (Slate et al., 2004) imply that the systems and handful set of markers we currently use to study GFCs should lack statistical power and may be biased, our results support the importance of inbreeding effects. First, it is unlikely that the number of inbred individuals has been artificially increased by a non-random sampling, since it is likely that our trapping method captured most of the individuals. Second, we used the same panel of markers in a previous study where the hypothesis of linkage disequilibrium was discarded (Lesbarrères et al., 2005). Therefore, it is unlikely that the association between genetic variability and offspring weight at metamorphosis was observed purely by chance.

Another significant result was the effect of genetic variability of the dam on offspring emergence from the pond. Maternal effects on offspring traits in amphibians are usually explained by differential investment in egg number and size (Kaplan, 1998; Laugen et al., 2002; Pakkasmaa et al., 2003; Räsänen et al., 2005). Our results
Table 4 Linear model of Rana temporaria offspring day of capture, from two populations accounting for effects of genetic variability of both the offspring $\left(H_{\mathrm{O}}\right)$, the sire $\left(H_{\mathrm{S}}\right)$ and the dam $\left(H_{\mathrm{D}}\right)$, the arrival day of both the sire $\left(A_{\mathrm{S}}\right)$ and the dam $\left(A_{\mathrm{D}}\right)$, the departure day of both the sire $\left(D_{\mathrm{S}}\right)$ and the dam $\left(D_{\mathrm{D}}\right)$, the offspring weight $\left(W_{\mathrm{O}}\right)$ and the pond they originated from (Pond)

\begin{tabular}{lcrc}
\hline Source & $d f$ & \multicolumn{1}{c}{$M S$} & $F$ \\
\hline$H_{\mathrm{O}}$ & 1 & 128.49 & 1.07 \\
$H_{\mathrm{S}}$ & 1 & 81.61 & 0.68 \\
$H_{\mathrm{D}}$ & 1 & 19.53 & 0.16 \\
$A_{\mathrm{S}}$ & 1 & 2.81 & 0.02 \\
$A_{\mathrm{D}}$ & 1 & 0.06 & 0.00 \\
$D_{\mathrm{S}}$ & 1 & 4.99 & 0.04 \\
$D_{\mathrm{D}}$ & 1 & 516.63 & $4.29^{*}$ \\
$W_{\mathrm{O}}$ & 1 & 0.19 & 0.00 \\
Pond & 1 & 1854.07 & $15.39^{* * *}$ \\
Model & 9 & & $2.41^{*}$ \\
Error & 23 & 120.46 & \\
$r^{2}$ & & 0.49 &
\end{tabular}

Abbreviations: df, degree of freedom; MS, mean square; $r^{2}$, coefficient of determination.

${ }^{*} P<0.05,{ }^{* * *} P<0.001$.

suggest the possibility that more heterozygous females are better at nourishing their eggs with yolk as compared with less heterozygous females (Danzmann et al., 1989). Further studies would be needed to investigate this relationship. An alternative possibility is that this association is a result of the non-independence of parent-offspring heterozygosity estimates (Mitton et al., 1993). Conversely, while previous studies have found genetic effects to be important determinants of growth rate, age and size at metamorphosis (e.g., Laugen et al., 2002), we did not observe any effect of male genetic variability.

We did not find any association between genetic variability and offspring capture date. Assuming that larval development is fairly constant within a pond, we propose that females leave the pond just after they have spawned and that environmental forces within the pond then drive the development of the larvae until dispersal. Similarly, in a previous common garden experiment, a lack of adaptive response to desiccation risk in northern larvae was observed (Laurila et al., 2002). Owing to the combined effects of water temperature and short growing season, this further suggests that environmental selection is strong enough to override genetic effects on developmental rates (Laugen et al., 2003) and favours rapid development in northern populations at the expense of phenotypic plasticity. Therefore, natural selection is likely to be the primary agent driving larval development and, although we used the offspring capture date as a proxy for time to metamorphosis, our results suggest that a more proximal cause of this trait variation might be the departure day of the female. In the trade-off between size and age at metamorphosis, there remains controversy regarding the possible correlation between these two traits (i.e., Gibbons and McCarthy, 1986; Miaud et al., 1999; Merilä et al., 2000). Similar to our results, size at metamorphosis was not related to timing of metamorphosis in an 8-year-study of $R$. temporaria (Loman, 2002). While timing of metamorphosis was influenced by temperature and dry-out events, size at metamorphosis was found to be influenced mostly by density effects (Loman, 2002). We suggest that size at 
metamorphosis is more important than time to metamorphosis in environments with strong selection pressure on the time to metamorphose (Merilä et al., 2004), hereby confirming the experimental results of Altwegg and Reyer (2003).

Our results also confirm the environmental dependency of early life history traits, since the pond effect significantly explained variation in both studied traits. This shows that local environment variation is important for tadpole development (Loman, 2002; Laugen et al., 2003), and that evolution of interpopulational differences in plastic responses is possible (Laurila et al., 2002). Pond $\mathrm{P}$ froze over for a short period after the first spawning had taken place, which prevented a large number of eggs from successfully hatching. Also, owing to lower water temperature in pond $\mathrm{P}$ as compared to pond $\mathrm{T}$ more tadpoles never finished metamorphosing. While the relationship between larval fitness trait variation investigated under controlled laboratory conditions and that seen at presumed-neutral microsatellite loci is not always observed (Rowe and Beebee, 2001a), our study identified such a correlation in the wild. Hence, our results suggest a disadvantage for homozygous individuals, particularly during stressful conditions (Crnokrak and Roff, 1999; Rowe and Beebee, 2003; Lesbarrères et al., 2005; Pearman and Garner, 2005).

Taken together, our results suggest that genetic variability is associated with offspring size at metamorphosis in $R$. temporaria with a disadvantage for homozygous individuals. Furthermore, this study revealed that dam genetic variability is associated with offspring size, which in turn determines fitness, as there is a higher probability of survival for bigger offspring. Finally, despite the constant debate over the genetic basis of GFCs, we suggest that amphibian populations provide good candidates to study fitness variation due to genome-wide heterozygosity.

\section{Acknowledgements}

This research was funded by CIMO (DL), the Swedish Research Council (JM), the Academy of Finland (CP, JM, DSS) and the KONE-Foundation Finland (DSS). We thank two anonymous reviewers as well as Valérie StAmour for their comments on a previous version of the paper.

\section{References}

Allendorf FW, Leary RF (1986). Heterozygosity and fitness in natural populations of animals. In: Soule ME (ed). Conservation Biology. Sinauer: Sunderland, MA. pp 57-76.

Altwegg R, Reyer HU (2003). Patterns of natural selection on size at metamorphosis in water frogs. Evolution 57: 872-882.

Balloux F, Amos W, Coulson T (2004). Does heterozygosity estimate inbreeding in real populations? Mol Ecol 13: 3021-3031.

Berlin S, Merilä J, Ellegren H (2000). Isolation and characterization of polymorphic microsatellite loci in the common frog, Rana temporaria. Mol Ecol 9: 1938-1939.

Berven KA, Gill DE (1983). Interpreting geographical variation in life-history traits. Am Zool 23: 85-97.

Crnokrak P, Roff DA (1999). Inbreeding depression in the wild. Heredity 83: 260-270.

Da Silva A, Luikart G, Yoccoz NG, Cohas A, Allainé D (2006). Genetic diversity-fitness correlation revealed by microsatellite analyses in European alpine marmots (Marmota marmota). Cons Gen 7: 371-382.

Danzmann RG, Ferguson MM, Allendorf FW (1989). Genetic variability and components of fitness in hatchery strains of rainbow trout. J Fish Biol 35: 313-319.

David P (1998). Heterozygosity-fitness correlations: new perspectives on old problems. Heredity 80: 531-537.

Duchesne P, Godbout M-H, Bernatchez L (2002). PAPA package for the analysis of parental allocation: a computer program for simulated and real parental allocation. Mol Ecol Notes 2: 191-193.

Fog K, Schmedes A, de Lasson DR (1997). Nordens Padder Og Krybdyr. GEC Gad: Copenhagen.

Gasc JP, Cabela A, Crnobrnja-Isailovic J (1997). Atlas of Amphibians and Reptiles in Europe. Societas Europaea Herpetologica and Muséum National d'Histoire Naturelle IEGB/ SPN: Paris.

Gibbons MM, McCarthy TK (1986). The reproductive output of frogs Rana temporaria (L.) with particular reference to body size and age. J Zool 209: 579-593.

Haapanen A (1982). Breeding of the common frog Rana temporaria L. Ann Zool Fenn 19: 75-79.

Hansson B, Westerberg L (2002). On the correlation between heterozygosity and fitness in natural populations. Mol Ecol 11: $2467-2474$.

Järvinen A (1987). Basic climatological data on the Kilpisjärvi area, NW Finnish Lapland. Kilpisjärvi Notes 10: 1-16.

Kaplan RH (1998). Maternal effects, developmental plasticity, and life history evolution: an amphibian model. In: Mousseau TA, Fox CW (eds). Maternal Effects as Adaptions. Oxford University Press: New York. pp 178-201.

Koskela P (1973). Duration of the larval stage, growth and migration in Rana temporaria L. in two ponds in northern Finland in relation to environmental factors. Ann Zool Fenn 10: $414-418$.

Laugen AT, Laurila A, Räsänen K, Merilä J (2003). Latitudinal countergradient variation in the common frog Rana temporaria developmental rates - evidence for local adaptation. J Evol Biol 16: 996-1005.

Laugen TA, Laurila A, Merilä J (2002). Maternal and genetic contributions to geographical variation in Rana temporaria larval life histories. Biol J Linnean Soc 76: 61-70.

Laurila A, Karttunen S, Merilä J (2002). Adaptive phenotypic plasticity and genetics of larval life histories in two Rana temporaria populations. Evolution 56: 617-627.

Lesbarrères D, Primmer CR, Laurila A, Merilä J (2005). Environmental and population dependency of genetic variability-fitness correlations in Rana temporaria. Mol Ecol 14: 311-323.

Loman J (2002). Temperature, genetic and hydroperiod effects on metamorphosis of brown frogs Rana arvalis and $R$. temporaria in the field. J Zool 258: 115-129.

Markert JA, Grant PR, Grant BR, Keller LF, Coombs JL, Petren K (2004). Neutral locus heterozygosity, inbreeding, and survival in Darwin's ground finches (Geospiza fortis and $G$ scandens). Heredity 92: 306-315.

McAlpine S (1993). Genetic heterozygosity and reproductive success in the green treefrog, Hyla cinerea. Heredity $\mathbf{7 0}$ 553-558.

Merilä J, Laurila A, Lindgren B (2004). Variation in the degree and costs of adaptive phenotypic plasticity among Rana temporaria populations. J Evol Biol 17: 1132-1140.

Merilä J, Laurila A, Timenes Laugen A, Räsänen K, Pahkala M (2000). Plasticity in age and size at metamorphosis in Rana temporaria - comparison of high and low latitude populations. Ecography 23: 457-465.

Merilä J, Sheldon BC (1999). Genetic architecture of fitness and nonfitness traits: empirical patterns and development of ideas. Heredity 83: 103-109.

Miaud C, Guyétant R, Elmberg J (1999). Variations in life-history traits in the common frog Rana temporaria 
Amphibia: Anura: a literature review and new data from the French Alps. I Zool 249: 61-73.

Miaud C, Merilä J (2001). Local adaptation or environmental induction? Causes of population differentiation in alpine amphibians. Biota 2: 31-50.

Mitton JB (1997). Selection in Natural Populations. Oxford University Press: Oxford, UK.

Mitton JB, Schuster WSF, Cothran EG, De Fries JC (1993). Correlation between the individual heterozygosity of parents and their offspring. Heredity 71: 59-63.

Mousseau TA, Fox CW (1998). The adaptive significance of maternal effects. Trends Ecol Evol 13: 403-407.

Pakkasmaa S, Merilä J, O'Hara RB (2003). Genetic and maternal effect influences on viability of common frog tadpoles under different environmental conditions. Heredity 91: 117-124.

Palo J, O'Hara RB, Laugen AT, Laurila A, Primmer CR, Merilä J (2003). Latitudinal divergence of common frog Rana temporaria life history traits by natural selection: evidence from a comparison of molecular and quantitative genetic data. $\mathrm{Mol}$ Ecol 12: 1963-1978.

Pearman PB, Garner TWJ (2005). Susceptibility of Italian agile frog populations to an emerging strain of Ranavirus parallels population genetic diversity. Ecol Lett 8: 401-408.

Pidancier N, Gauthier P, Miquel C, Pompanon F (2002). Polymorphic microsatellite DNA loci identified in the common frog Rana temporaria, Amphibia, Ranidae. Mol Ecol Notes 2: 304-305.

R Development Core Team (2003). R: A Language and Environment for Statistical Computing. R Foundation for Statistical Computing: Vienna, Austria.

Räsänen K, Laurila A, Merilä J (2005). Maternal investment in egg size: environment- and population-specific effects on offspring performance. Oecologia 142: 546-553.

Richter SC, Young JE, Johnson GN, Seigel RA (2003). Stochastic variation in reproductive success of a rare frog, Rana sevosa: implications for conservation and for monitoring amphibian populations. Biol Conserv 111: 171-177.

Roff DA (1992). The Evolution of Life Histories. Chapman \& Hall: New York, NY, USA.

Roff DA (1997). Evolutionary Quantitative Genetics. Chapman \& Hall: NY, USA.
Rowe G, Beebee TJC (2001a). Fitness and microsatellite diversity estimates were not correlated in two outbred anuran populations. Heredity 87: 558-565.

Rowe G, Beebee TJC (2001b). Polymerase chain reaction primers for microsatellite loci in the common frog Rana temporaria. Mol Ecol Notes 10: 6-7.

Rowe G, Beebee TJC (2003). Population on the verge of a mutational meltdown? Fitness costs of genetic load for an amphibian in the wild. Evolution 57: 177-181.

Rowe G, Beebee TJC, Burke T (1999). Microsatellite heterozygosity, fitness and demography in natterjack toads Bufo calamita. Anim Conserv 2: 85-92.

Ryser J (1989). Weight loss, reproductive output, and the cost of reproduction in the common frog, Rana temporaria. Oecologia 78: 264-268.

Slate J, David P, Dodds KG, Veenvliet BA, Glass BC, Broad TE et al. (2004). Understanding the relationship between the inbreeding coefficient and multilocus heterozygosity: theoretical expectations and empirical data. Heredity 93: 255-265.

Slate J, Kruuk LEB, Marshall TC, Pemberton JM, Clutton-Brock TH (2000). Inbreeding depression influences lifetime breeding success in a wild population of red deer (Cervus elaphus). Proc R Soc Lond B Biol Sci 267: 1657-1662.

Smith DC (1987). Adult recruitment in chorus frogs: effects of size and date at metamorphosis. Ecology 68: 344-350.

Sokal RR, Rohlf FJ (1995). Biometry the Principles and Practice of Statistics in Biological Research. Freeman WH and Co: NY, USA.

Tsitrone A, Rousset F, David P (2001). Heterosis, marker mutational processes and population inbreeding history. Genetics 159: 1845-1859.

van Oosterhout C, Hutchinson WF, Wills DPM, Shipley PF (2004). MICRO-CHECKER: software for identifying and correcting genotyping errors in microsatellite data. Mol Ecol Notes 4: 535-538.

Vos CC, Antonisse-De Jong AG, Goedhart PW, Smulders MJM (2001). Genetic similarity as a measure for connectivity between fragmented populations of the moor frog Rana arvalis. Heredity 86: 598-608.

Wells KD (1977). The courtship of frogs. In: Taylor DH, Guttman SI (eds). The Reproduction Biology of Amphibians. Plenum Press: NY, USA. pp 233-262. 